\title{
System-wide impacts of provider-payment reforms: evidence from the health sectors of Central and Eastern Europe and Central Asia R Moreno-Serra*1, R Moreno-Serra ${ }^{2}$ and A Wagstaff ${ }^{3}$
}

Address: ${ }^{1}$ Centre for Health Economics, University of York, York, UK, ${ }^{2}$ Department of Economics, University of York, York, UK and ${ }^{3}$ Development Research Group, The World Bank, Washington, DC, USA

* Corresponding author

from 25th Patient Classification Systems International (PCSI) Working Conference Fukuoka, Japan. II-I4 November 2009

Published: 5 November 2009

BMC Health Services Research 2009, 9(Suppl I):A2 doi:I0.II86/1472-6963-9-SI-A2

This abstract is available from: http://www.biomedcentral.com/I472-6963/9/SI/A2

(c) 2009 Moreno-Serra et al; licensee BioMed Central Ltd.

\section{Introduction}

Only a small portion of today's existing research has made use of rigorous empirical methods to convincingly isolate the impact on the health sector of the new provider-payment arrangements from those which resulted from other changes occurring at the same time. Throughout the 1990 s and early 2000s, several transitional countries in Central and Eastern Europe and Central Asia (ECA) aimed at reforming their provider-payment systems in order to achieve the general objectives of protecting health-spending levels and improving the overall performance of the health sector.

We use such reforms as a natural experiment to investigate, empirically, the system-wide impacts of introducing patient-based (casemix) and fee-for-service methods for hospital reimbursement (compared to line-item budgets) on a set of outcomes including hospital-activity rates, capacity utilization, national-health spending, and mortality amenable to healthcare.

\section{Methods}

Using panel data gathered from 28 ECA countries from 1990 to 2004, and controlling for - among other factors contemporaneous payment reforms in the primary-care sector, our three regression-based generalizations of the difference-in-differences approach seem to account adequately for the potential endogeneity of payment-method reforms.

\section{Results}

At the hospital level, our results indicate that patientbased/casemix payment reduces the average length-ofstay by approximately $4 \%$, and the bed-occupancy rate by $5 \%$ (with no perceptible effect on inpatient admissions). Fee-for-service methods, on the other hand, increase admissions by almost $8 \%$, and the bed-occupancy rate by a similar magnitude. At the broader health-sector level, both payment arrangements raise per-capita health spending by a similar amount (approximately 20\%), with equally large effects on both public and private spending.

Finally, we do not find evidence that using fee-for-service in preference to budgets has any effect on amenable mortality. However, significantly negative effects on the death rates for two causes - in addition to generally negative point estimates for the remaining measures - are found due to the introduction of patient-based methods.

\section{Conclusion}

Overall, our results provide evidence that patient-based/ casemix and fee-for-service hospital-payment methods have different effects, both at the hospital level and for the health sector as a whole. Both hospital-payment arrangements increase the amount of resources going into the health system (with potentially important distributional consequences), yet patient-based/casemix systems seem to do better in translating the additional resources into improved population health. 